\title{
Clinical manifestations of tall fescue (Festuca arundinacea) and perennial ryegrass (Lolium perenne) toxicosis in Oregon and Japan
}

\author{
L. L. BLYTHE, A. M. CRAIG, C. ESTILL and C. CEBRA \\ College of Veterinary Medicine, Oregon State University, Corvallis, OR, USA
}

Linda.blythe@oregonstate.edu

\begin{abstract}
There are multiple vehicles for endophyte toxicosis in animals including exposure from pasture, straw residues and seed screenings. This report discusses the clinical cases typically seen with tall fescue and perennial ryegrass toxicosis in Oregon and Japan. Case I involves a herd of 330 Black Angus cattle. Before the March calving season the owner wished to increase the protein content of the feed ration by feeding pellets made of seed screenings and grass hay. Forty two animals were lost to tall fescue toxicosis and dry gangrene of the feet and legs. Case II involves 1300 beef cows in Eastern Oregon fed grass straw; 485 animals were lost due to dry gangrene characteristic of tall fescue toxicosis. Case III describes 4 of 15 cases of both tall fescue and perennial ryegrass toxicosis in Japanese black cattle. Case IV involves llamas and alpacas on pasture and lawn paddocks where some animals were affected by tall fescue and some by perennial ryegrass.
\end{abstract}

Keywords: tall fescue, Festuca arundinacea L., perennial ryegrass, Lolium perenne, endophyte, Neotyphodium coenophialum, Neotyphodium lolii

\section{Introduction}

Tall fescue (Festuca arundinacea L.) is a perennial grass grown in the Willamette Valley of Oregon, predominately for seed production. A fungal endophyte (Neotyphodium coenophialum) in the grass and resultant seed gives growing plants increased protection from insects, disease, and drought (Bacon 1988). Perennial ryegrass (Lolium perenne) is also grown for seed and has a unique fungal endophyte (Neotyphodium lolii) which also protects plants from some insects, drought, and disease. Oregon grows approximately $70 \%$ of the world's supply of tall fescue and perennial ryegrass seed. Since the primary market is for grass seed for lawns, golf courses, and parks for both types of grasses, these protective characteristics from the fungus are highly desirable. Multiple varieties of seed are marketed with endophyte levels ranging from none to low, medium, or high concentrations of the fungus.

Endophyte fungus in tall fescue produces at least ten

Figure 1 Fescue foot in a cow's pelvic limb.

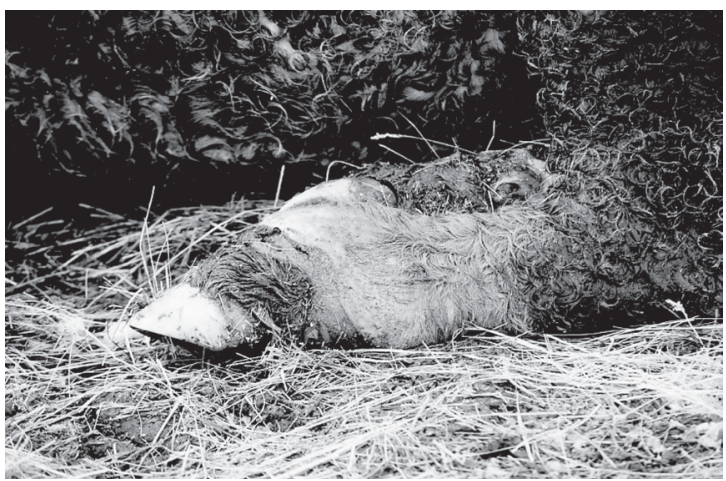

ergopeptine alkaloids at varying concentrations during plant growth from sprouting to maturation. Some alkaloids, such as peramine, produced in the highest quantities during early growth, inhibit insect predation. In more mature plants, alkaloids in highest concentration such as egrovaline, can have deleterious effects on livestock ingesting it (Joost 1995; Porter 1995). Summer syndrome in cattle is characterised by heat intolerance and inappetence; it is most prevalent in hot humid summers in southeastern United States. Ingestion of the same toxin in cold climates can result in vasoconstriction of the blood supply to the feet, ears, and tails with resultant dry gangrene or "fescue foot" in severely affected cases (Tor-Agbidye et al. 2001; AldrichMarkham et al. 2003). Typically, 2 to 3 weeks after cattle ingest high levels of endophytic toxins, clinical signs appear. Not all animals are equally affected. Tall fescue straw, while a residue of seed production, is a good nutritive source of fibre for livestock and is often fed in combination with higher quality hays such as alfalfa.

Endophyte-infected perennial ryegrass produces a number of lolitrem alkaloids (Gallagher et al. 1984; Rowan 1993) including lolitrem A, B, C, D, and E as well as lesser amounts of ergovaline (Hovermale \& Craig 2001). While all the lolitrems are suspected of being tremorgens, it is lolitrem B that is highest in concentration in the plant material and is believed to cause clinical signs of ryegrass staggers. Thus, lolitrem B is measured in defining threshold toxicity. Ryegrass staggers is the disease produced in horses, cattle, and sheep ingesting perennial ryegrass pasture or straw, or pellets with perennial ryegrass seed screenings containing lolitrem B (Hunt et al. 1983; Galey et al. 1991). When animals are fed high levels (1800 to $2000 \mathrm{ppb}$ lolitrem B) as a sole source of feed, clinical signs of the disease usually become evident in 1 to 2 weeks (Blythe et al. 1993; Fisher et al. 2004). Initial signs are a stiff limb gait with proprioception deficits (knowing where the body is in space). This progresses to ataxia and muscle tremors and reluctance or an inability to rise. Excitement worsens clinical signs, especially the ataxia and the gross muscle tremors in major muscles of the limbs. Animals not withdrawn from the high levels of lolitrem $B$ in feed can exhibit a down convulsive state but seldom die. Most fatalities are a result of animals in pasture situations getting into river gullies or under farm fencing and being recumbent in such a way that they bloat. A case is reported where calves ingesting perennial ryegrass developed a concurrent pulmonary emphysema, however, this

Table 1 Ergot alkaloids found in seed screenings from four bins in different locations (Case I). Bolded numbers are above the threshold for toxicity.

\begin{tabular}{lcc}
\hline Sample ID & Ergovaline $(\mathrm{ppb})$ & Ergotamine $(\mathrm{ppb})$ \\
\hline North1 & $\mathbf{9 3 7}$ & 340 \\
North 2 & 179 & $\mathbf{1 8 7 0}$ \\
West & $\mathbf{1 2 0 6}$ & 540 \\
Home & $\mathbf{1 0 3 7}$ & 340 \\
\hline
\end{tabular}


Table 2 Ergovaline concentrations in samplings of four tall fescue straw stacks (Case II). Each stack was sampled twice ( $a$ and $b)$.

\begin{tabular}{ccc}
\hline Stack & Sample ID & Ergovaline $(\mathrm{ppb})$ \\
\hline 1a & Ranch 1 & 355 \\
1b & Ranch 1 & 959 \\
2a & Ranch 2 & 1047 \\
2b & Ranch 2 & 1221 \\
3a & Ranch 3 & 1094 \\
3b & Ranch 3 & 1158 \\
4a & Ranch 4 & 1290 \\
4b & Ranch 4 & 1011 \\
\hline
\end{tabular}

could not be reproduced experimentally with the same feed (Pearson et al. 1996). Withdrawing the animal from feed usually results in a return to normal in several days, although in some, it may take a few weeks depending on the severity of the signs.

A definitive diagnosis of either tall fescue toxicosis or ryegrass staggers depends on quantitation of respective alkaloid levels in feed. In the ergovaline assay, straw is ground to $0.5 \mathrm{mms}$, partitioned into chloroform by shaking for 24 hours, purified by an SPE column, and quantitated by a HPLC fluorescence assay (Craig et al. 1994). The concentration appropriate for clinical disease is in parts per billion (ppb). For the lolitrem B assay, straw is ground to $0.5 \mathrm{mms}$ and partitioned into a chloroform methanol mixture. After shaking for 18 hours, the mixture is evaporated to dryness, reconstituted into a chloroform/acetonitrile mixture, and quantitated by an HPLC fluorescence assay (Hovermale \& Craig 2001)

This paper presents a series of clinical cases occurring in the Pacific Northwest and some cases reported from Japan involving both tall fescue toxicosis and perennial ryegrass toxicosis and the ergovaline and lolitrem B levels associated with each.

\section{Case Studies}

\section{Case I}

Three hundred and thirty cows on a ranch, in the lower Willamette Valley were affected by fescue toxicosis. The owner had two ranches that were 40 miles apart with cattle on them. They were both hilly terrain with natural, long established, unimproved pasture grasses of brome and meadow grasses. Both ranches had successfully served as a pasture for a cow/calf operation for a number of years. On ranch 1 there were 330 pure bred Angus, 320 cows with 250 expected to calf and 10 bulls. Ranch 2 was a second cow/calf operation with 57 animals including one bull. Ages of cattle varied between 2 and 7. Grass hay for both ranches had been purchased off the same field. Calving was to begin in March/April on both ranches. To increase the protein of the ration on Ranch 1, the owner purchased 20 tonnes of pelleted feed that contained seed screenings of tall fescue, grass hay, and a binder. These were given ad libitum via feed bunkers in the pasture starting the second week in December, 2005. The first case was seen in the first week of January and was misdiagnosed as a wire cut. During January, there was a week long cold spell with temperatures falling to $-7^{\circ} \mathrm{C}$. By early February, there were initially three lame cattle with severe dry gangrene of one or more limbs. By February 20, 15 had died or been euthanased, three aborted foetuses were found in the pasture, and seven more cows were severely affected and subsequently were destroyed. Figure 1 illustrates a typical lesion of dry gangrene. On February 17, these limbs were processed by the veterinary diagnostic laboratory at Oregon State University (OSU) and found to be typical of fescue foot. Subsequently, feeding pellets was terminated and alfalfa hay was supplemented. Samples from the four bins of pellets were taken and analysed by HPLC for ergovaline (Craig et al. 1994; Duringer et al. 2005). Both ergovaline and ergotamine were found (Table 1).

\section{Case II}

A family owned crossbred beef cow/calf operation with over 1800 animals in Harney County, Eastern Oregon had animals in three separate herds. Two of the herds, A with 1040 animals and B with 260 cows, were fed from common stacks of tall fescue straw purchased from the Willamette Valley in Oregon. Due to summer and fall drought conditions, sufficient feed was not available from local sources. Starting in late November, tall fescue straw was initially fed as the sole fibre supplement along with residual autumn pasture grazing. On January 17, all feeding of tall fescue stopped. The 500 cows in Herd $\mathrm{C}$ were fed fine fescue straw and meadow hay.

Clinical signs of lameness and swollen feet were first noted by the owners in cows in herds A and B on December 25. Signs progressed to dry gangrene of the feet, often with subsequent fracture of the necrotic toes or lower limbs. By March 5 in Herd A, 449 animals had died or were euthanased due to fescue foot, 56 were lame, and 12 had uterine prolapses. In Herd B, 36 were dead or destroyed, 49 were lame, and three had uterine prolapses. Abortions and birth of weak or dead calves occurred in the majority of pregnant cows affected. Herd $\mathrm{C}$ had no clinical problems. The minimum environmental temperatures from November 25 to December 25 , ranged from -17 to $-1^{\circ} \mathrm{C}$ with 16 days of minimum temperatures less than $-12^{\circ} \mathrm{C}$.

Core samples of remaining tall fescue straw were taken on January $17^{\text {th }}$ with subsequent analyses for ergovaline concentrations. Willamette Valley tall fescue straw had been delivered in 20 ton shipments and contained straw from more than one field. Table 1 lists values for the duplicate sampling (a and b) of each of the four stacks. Some sections of the stack were found to have high ergovaline content (stacks 2, 3, and 4) while others had lower ergovaline concentrations (stack 1a). The mean concentration of ergovaline in all stacks was $1016.9 \pm 289.0 \mathrm{ppb}$. Forty tonnes of tall fescue straw had been consumed in November and December 2002 before testing.

The combination of low environmental temperatures and high levels of ergovaline toxin in endophyte positive tall fescue resulted in a catastrophic loss of cattle to this family. Not only were mother cows and their calves lost, but 25 of 40 of their bulls were also fatally affected. Vasoconstriction of the extremities resulted in sufficient necrosis that the majority of the animals were unable to recover. A previous study set the threshold for fescue toxicosis at 400 to $750 \mathrm{ppb}$ in cattle (Tor-Agbidye et al. 2001).

\section{Case III}

Oregon produces and exports over 660000 tonnes (33 000 containers) of grass straw to Japan, Korea, and Taiwan. The grass seed and straw exporters work with the Endophyte Testing Laboratory at OSU to determine levels of lolitrem B and ergovaline in straw shipments to be exported. The University laboratory provides a certificate to exporters listing toxin levels. This is a voluntary testing programme and not all exporters use 
Table 3 Lolitrem B concentrations in cow tissues (Miyazaki et al. 2004).

\begin{tabular}{|c|c|c|c|c|c|c|c|c|}
\hline \multicolumn{2}{|c|}{ Cow } & \multirow{2}{*}{$\begin{array}{l}\text { Feeding } \\
\text { duration }\end{array}$} & \multicolumn{6}{|c|}{ Lolitrem B (ppb in wet tissue) } \\
\hline Group & No. & & Muscle & Liver & Kidney & Heart & Cerebrum & Fat \\
\hline 1 & 1 & $15 d$ & $N^{*}$ & ND & ND & ND & ND & 210 \\
\hline \multirow[t]{3}{*}{2} & 1 & $5 \mathrm{wk}$ & ND & ND & ND & ND & NT† & 130 \\
\hline & 2 & $13 w k$ & ND & ND & ND & ND & NT & 123 \\
\hline & 3 & $16 \mathrm{wk}$ & ND & ND & ND & ND & NT & 144 \\
\hline
\end{tabular}

it resulting in some of both tall fescue and perennial ryegrass with high (suprathreshold) levels of ergovaline and lolitrem B, respectively being delivered to Japan.

A 1998 report from Japan stated there were 29 cases of ryegrass staggers in cattle and horses fed imported perennial ryegrass straw from Oregon (Saiga \& Maejima); levels of toxicity ranged from $970 \mathrm{ppb}$ to $3700 \mathrm{ppb}$. In addition, a 1998 Japanese publication stated Japanese black cattle are more susceptible and the toxin threshold values proposed by OSU should be revised (Saiga 1998). A recent Japanese publication (Miyazaki et al. 2004) proposed toxic levels of lolitrem B to be approximately $1200 \mathrm{ppb}$ with safety threshold levels at $<600 \mathrm{ppb}$.

At a 2006 meeting between representatives of the United States National Hay Association, the Director of the Endophyte Testing Laboratory at Oregon State University (A. M. Craig), and officials from the Ministry of Agriculture, Forestry and Fisheries (MAFF) division of the Japanese Ministry of Agriculture, a report was given on 15 cases of endophyte toxicosis. Japanese veterinarians initially saw these cases and straw samples were then sent to MAFF for testing to support the tentative diagnosis of either ryegrass staggers due to feeding endophyte-infected perennial ryegrass or fescue foot caused by feeding endophyte-infected tall fescue. The straw was analysed and values for ergovaline or lolitrem B were determined. The following describes examples of these cases and the level of endophyte toxins associated with each:

Example 1 Tall fescue straw was imported into Japan on September 2005. It was fed to 120 beef animals; five developed anorexia and lameness and one became recumbent and was euthanased. MAFF reported ergovaline levels at $1230 \mathrm{ppb}$. In this case, the fate of the other four affected animals was unknown. In Japanese feeding practices, it is typical to mix tall fescue with varying amounts of beerwort or mash as a protein source in a total mixed ration (TMR). The dilution of tall fescue straw in the TMR was not known.

Example 2 In November 2005 endophyte-infected perennial ryegrass was imported into Okinawa and fed to 380 Waygu beef cattle; 120 animals became affected with clinical signs of ryegrass staggers described as "walking difficulties." When these clinical signs were seen, feed was changed and all recovered except for one death. The perennial ryegrass straw contained $2710 \mathrm{ppb}$ lolitrem B. With lolitrem B levels this high in the United States, clinical signs of ryegrass staggers usually start appearing on day 7 to 10 of feeding and grow worse with each day if the ryegrass is fed as $100 \%$ of the ration. The dilution of straw in this case was unknown as was the time course of the disease. Death due to ryegrass staggers is unusual.

Example 3 Fescue toxicosis affecting 10 out of 20 cattle was associated with tall fescue straw containing $520 \mathrm{ppb}$. Two animals died and the remaining had difficulty walking with one unable to rise.

Example 4 Perennial ryegrass shipped into Japan in January 2006 was believed to have caused ryegrass staggers in cattle in two locations. In one location straw was fed containing $3100 \mathrm{ppb}$ lolitrem B and in the other, the suspect straw contained $1900 \mathrm{ppb}$ lolitrem B. Sample analyses were the only data presented.

This collection of cases shows clinical disease associated with high levels of endophyte toxins. This has important political and economical impacts on the relationship between the Japanese and Pacific Northwest. The Japanese want assurance that feed exported from the United States is safe. It is apparent from these reported cases given to the authors by the Japanese Ministry of Agriculture that additional information is needed on the amount and length of time endophyte-infected straw was fed, the level of dilution with other feeds, and detailed clinical and pathological features of the diseases, especially those thought to be fescue foot. All of these cases, however, developed at toxin levels above published threshold levels and were comparable to levels found in clinical cases in the United States. There were no cases of disease in this report with the toxins at threshold or subthreshold toxin levels.

Case IV Endophyte toxins are also suspected to affect New World camelids. Poor milk production is common in alpacas and frequently blamed on feeding endophyte-infected tall fescue. Domperidone has been used therapeutically with some reported success. Sloughing of distal extremities was also seen in one llama herd exposed to endophyte-infected tall fescue. Tremorgenic toxins were also suspected in several outbreaks of neurologic disease. In 2003, six alpacas in one Oregon herd developed tremors during movement (intention tremors) and hypermetria that appeared to resolve after a feed change. In the Midwest, a number of alpacas developed similar signs during and after an exhibit displaying the animals. The paddocks where the animals were housed had been covered with residential turf grass; a high endophyte content was suspected but not confirmed. In general, diagnoses were not pursued; therefore, these occurrences remain anecdotal. Toxic thresholds for camelids have not been determined for either lolitrem B from endophyteinfected perennial ryegrass or ergovaline or other ergot alkaloids from endophyte-infected tall fescue.

\section{Discussion}

Endophyte associated diseases seen in the Pacific Northwest and in Japan are fescue foot, due to endophyte-infected tall fescue, and ryegrass staggers, due to endophyte-infected perennial ryegrass. 
"Summer slump" is seen in animals on endophyte-infected tall fescue pastures in the southeastern areas of the United States where hot and humid environmental conditions exist. Fescue foot occurs during winter months when temperatures are near or below freezing, even for short periods (several days). Vasoconstriction from the cold temperatures coupled with the vasoconstriction caused by ergovaline and the other ergot alkaloids stop adequate blood supply to the lower limb extremities and dry gangrene results. In contrast, ryegrass staggers can occur in any season.

Knowledge of endophyte toxins levels in straw before it is fed is the key to ending endophyte diseases. Endophyte-infected straws with levels above threshold can either not be fed or be diluted with other feed to give a daily dose below threshold. In trials with Japanese black cattle, perennial ryegrass with 1200 ppb was fed either as sole feed ad libitum with average daily ingestion of $6.5 \mathrm{~kg}$ straw per day (Group 1) or diluted 50:50 with other feed for a total daily ration of $3 \mathrm{~kg}$ straw per day (Group 2). Clinical signs were seen in Group 1 (3/3 animals) after 12 to 15 days; feeding was stopped on day 15 . In Group 2, no clinical signs of ryegrass staggers were observed during the 16 week feeding trial (Miyazaki et al. 2004).

Neither ergovaline nor lolitrem B is considered a cumulative toxin like the pyrrolizidine alkaloid toxins found in many plants (Craig et al. 1986). Threshold levels were determined in feeding trials that extended over 28 days (Blythe et al. in press) to 3 months (Fisher et al. 2004). No clinical signs were seen in any Angus and Angus cross bred cattle or Japanese black cattle crossbreeds with lolitrem B at 1400 to $1550 \mathrm{ppb}$ during these times. Clinical signs of ryegrass staggers, however, were seen in Japanese black cattle in Japan when straw with 1000 ppb was consumed over 90 days (Miyazaki 2006 personal communication). These conflicting results need further investigation; threshold values may need to be adjusted relative to the time of feeding.

Another question raised by the Japanese feeding trials concerns the public health significance of lolitrem $\mathrm{B}$ residues found only in fat tissue, even with sub-clinical levels of lolitrem B in perennial ryegrass straw (Miyazaki et al. 2004). Residue values are listed in Table 3. In experiments conducted in Oregon, fat residues found after 28 days of feeding a high dose of lolitrem B (mean 2574 ppb lolitrem B for 4 weeks with a high of $3000 \mathrm{ppb}$ lolitrem B for the last 2 weeks) were $51 \mathrm{ppb}$ and $61 \mathrm{ppb}$. These fat levels are lower than those found in the Japanese study in cattle fed with lower levels of lolitrem B over a longer time (Table 3). The significance of lolitrem B residues found in fat remains to be investigated.

\section{ACKNOWLEDGEMENTS}

This paper is based upon work supported by the Oregon Agriculture Experiment Station and the U.S. Department of Agriculture under Agreement No. 58-6227-4-0021. Any opinions, findings, conclusion or recommendations expressed in this publication are those of the author(s) and do not necessarily reflect the view of the U.S. Department of Agriculture.

\section{REFERENCES}

Aldrich-Markham, S.; Pirelli, G.; Craig, A.M. 2003. Endophyte toxins in grass seed fields and

straw effects on livestock. Oregon State Extension Service Publication EM 8598.

Bacon, C.W. 1988. Procedure for isolating the endophyte from tall fescue and screening isolates for ergot alkaloids. Applied and Environmental Microbiology 54: 2615-2618.

Blythe L.L.; Tor-Agbidye, J.; Craig, A.M. 1993. Correlation of quantities of lolitrem B toxin to clinical field cases of ryegrass staggers. Mycotoxicoses of Grassland Farming Symposium, Hamilton, New Zealand, September 1993. New Zealand Veterinary Journal 41: 217.

Craig, A.M.; Bilich, D.; Hovermale, J.T.; Welty, R.E. 1994. Improved extraction and HPLC methods for ergovaline from plant material and rumen fluid. Journal of Veterinary Diagnostic Investigation 6: 348-352.

Craig, A.M.; Blythe, L.L.; Lassen, E.D.; Slizeski, M.L. 1986. Resistance of sheep to pyrrolizidine alkaloids. Israel Journal of Veterinary Medicine 42: 376-384.

Duringer, J.M.; Lewis, R.; Kuehn, L.; Fleischmann, T.; Craig, A.M. 2005. Growth and hepatic in vitro metabolism of ergotamine in mice divergently selected for response to endophyte toxicity. Xenobiotica 35: 531-548.

Fisher, M.J.; Bohnert, D.W.; Ackerman, C.J.; Schauer, C.S.; DelCurto, T.; Craig, A.M.; Vanzant, E.S.; Harmon, D.L.; Schrick, F.N. 2004. Evaluation of perennial ryegrass straw as a forage source for ruminants. Journal of Animal Science 82: 2175-2184.

Galey, F.D.; Tracy, M.L.; Graigmill, M.L.; Barr, B.C.; Markegard, G.; Peterson, R.; O’Conner, M. 1991. Staggers induced by consumption of perennial ryegrass in cattle and sheep from northern California. Journal of the American Veterinary Medical Association 199: 466-470.

Gallagher R.T.; Hawkes, A.D.; Steyn, P.S.; Veleggaar, R. 1984. Tremorgenic neurotoxins from perennial ryegrass causing ryegrass staggers disorder of livestock: Structure elucidation of lolitrem B. Journal of the Chemical Society, Chemistry Communication III: 614-666.

Hovermale, J.T.; Craig, A.M. 2001. Correlation of ergovaline and lolitrem B levels in endophyte infected perennial ryegrass (Lolium perenne). Journal of Veterinary Diagnostic Investigation 13: 323-327.

Hunt, L.D.; Blythe, L.L.; Holtan, D.W. 1983. Ryegrass staggers in ponies fed processed ryegrass straw. Journal of the American Veterinary Medical Association 182: 285-286.

Joost, R. 1995. Acremonium in fescue and ryegrass: boon or bane? A review. Journal of Animal Science 73: 881-888.

Pearson, E.G.; Andreasen, C.B.; Blythe, L.L.; Craig, A.M. 1996. Atypical pneumonia associated with ryegrass staggers in 17 calves. Journal of the American Veterinary Medical Association 209: 1137-1142.

Miyazaki, S.; Ishizaki, I.; Ishizaka, M.; Kangara, T.; IshiguroTakeda, Y. 2004. Lolitrem B residue in fat tissues of cattle consuming endophyte-infected perennial ryegrass straw. Journal of Veterinary Diagnostic Investigation 16: 340-342.

Porter, J. 1995. Analysis of endophyte toxins: fescue and other grasses toxic to livestock. Journal of Animal Science 73: 871-880.

Rowan, E. 1993. Lolitrems, peramine, and paxilline: Mycotoxins of the ryegrass/endophyte interaction. Agriculture, Ecosytems and Environment 44: 103-122.

Saiga, S. 1998. Frequent occurrence of cattle poisoning through endophyte-infected hay. pp. 21-25 In:Livestock Technique.

Saiga, S.; Maejima, A. 1998. Livestock poisoning caused by ryegrass straw produced in Oregon, USA. Journal of Tohoku Livestock Science and Technology 47: 44-46.

Tor-Agbidye, J.; Blythe, L.L.; Craig, A.M. 2001. Correlation of endophyte toxins (ergovaline and lolitrem B) with clinical disease: Fescue Foot and Perennial Ryegrass Staggers. Veterinary and Human Toxicology 43: 140-146. 